\title{
WEIGHTED INEQUALITIES OF HARDY TYPE FOR MATRIX OPERATORS: THE CASE $q<p$
}

\author{
Ryskul OinAROv, Christopher A. OKPOTI AND LARS-ERIK PERSSON
}

Abstract. A non-negative triangular matrix operator is considered in weighted Lebesgue spaces of sequences. Under some additional conditions on the matrix, some new weight characterizations for discrete Hardy type inequalities with matrix operator are proved for the case $1<q<p<\infty$. Some further results are pointed out.

Mathematics subject classification (2000): 26D10, 26D15.

Key words and phrases: inequalities, discrete Hardy type inequalities, weights, matrix operators.

\section{REFERENCES}

[1] K. F. ANDERSEN, H. HeINIG, Weighted norm inequalities for certain integral operators, SIAM J. Math. 14, (1983), 834-844.

[2] G. BENNETT, Some elementary inequalities III, Quart. J. Math. Oxford Ser., 42, (2) (1991), 149-174.

[3] K. Goswin, G. ERDMANn, The Blocking Technique, Weighted Mean Operators and Hardy's Inequality, Springer-Verlag, 1998.

[4] A. Kufner, L.-E. Persson, Weighted Inequalities of Hardy type, World Scientific Publishing Co, Singapore/New Jersey/London/Hong Kong, 2003.

[5] A. Kufner, L. Maligranda And L.-E. Persson, The prehistory of the Hardy inequality, Amer. Math. Monthly, 113, (8) (2006), 715-732.

[6] A. KufNer, L. MALIGRANDA AND L.-E. Persson, The Hardy inequality - About its history and some related results, Vydavatelsky Servis Publishing House, Pilsen, 2007.

[7] R. OINAROV, A dual inequality at the additive estimate of matrix operator (Russian). Proc. Intern. conf. "Achievement and development of mathematics in framework of program- Kazakhstan in third millennium" (Almaty, October 26-28, 2000), Almaty, 2001, 111-115.

[8] R. Oinarov, S. Kh. Shalginbayeva, Weighted additive estimate of one class of matrix operators, Izvestiya NAN RK, serial Phys.-Mat., (1) (2004), 39-49.

[9] C. A. OKPOTI, Weight characterizations of discrete Hardy and Carleman type inequalities, Licentiate Thesis, Department of Mathematics, Luleå University of Technology, Sweden, (45) 2005 (81 pages).

[10] C. A. OKPOTI, L.-E. PERSSON AND A. WedESTIG, Weight characterizations of discrete Hardy inequality with kernel, J. Inequal. Appl., 2006, (2006), Article ID 18030. 